\title{
Laços, desafios agroecológicos e transformações em Nova Iguaçu (RJ): um breve estudo de caso
}

Suziane Hermes de Mendonça Soares ${ }^{1}$ Cristhiane Oliveira da Graça Amâncio ${ }^{2}$

\section{Resumo}

Este estudo de caso busca compreender a Escolinha de Agroecologia como instrumento de fortalecimento cultural e de identidade, focalizando a cidade de Nova Iguaçu (RJ), ao identificar uma territorialidade rural na proposta por tal práxis. Foram utilizadas informações da EMATER, dos anos de 2008 a 2015, somando-as às evidências empíricas relatadas pelos técnicos deste órgão para a construção de dados que complementassem o caso estudado e norteassem a aplicação da metodologia. A pesquisa encontrou na Escolinha de Agroecologia um esforço geral para destacar a importância da educação popular para os agricultores de Nova Iguaçu, fortalecendo a identidade e a reprodução social da cultura rural, mesmo numa localidade de grande expressão urbana. No entendimento dos agricultores, quanto maior os esforços feitos para uma aproximação com o território, mais as desigualdades internas se tornam visíveis e passíveis de serem superadas.

Palavras-chave: Agroecologia. Agricultura familiar. Sustentabilidade.

\begin{abstract}
This case study seeks understanding the Little School of Agroecology as cultural strengthening instrument and identity, focusing on the city of Nova Iguaçu (RJ) identifying the rural territoriality in the proposal by such practice. Was used information from EMATER, from the years 2008 to 2015, adding to the empirical evidence reported by the technicians of this body to construct data that complemented the case studied and guided the application of the methodology. The research found in the School of Agroecology a general effort to emphasize the importance of popular education for farmers in Nova Iguaçu, strengthening the identity and social reproduction of rural culture, even in a town with great urban expression. In the understanding of the farmers, the greater the efforts made to approach the territory, the more internal inequalities become visible and can be overcome.
\end{abstract}

Keywords: Agroecology. Family farming. Sustainability.

\footnotetext{
${ }^{1}$ Mestre em Desenvolvimento Territorial e Políticas Públicas, Universidade Federal Rural do Rio de Janeiro. suzianehmsoares@gmail.com.

2 Doutora em Ciências Sociais com ênfase em Desenvolvimento, Agricultura e Sociedade. Professora da Universidade Federal Rural do Rio de Janeiro. cristhiane.amancio@embrapa.gov.br.
} 


\section{Introdução}

Este artigo tem por objetivo analisar os instrumentos das dimensões da territorialidade na cidade de Nova Iguaçu (RJ), com o intuito de caracterizar as novas percepções no desenvolvimento rural executadas nessa localidade através da Agroecologia junto aos agricultores, bem como o poder social gerado.

A construção do discurso agroecológico tem sido promovida através da concepção e realização do curso de Agroecologia denominado Escolinha de Agroecologia de Nova Iguaçu (EA), no Rio de Janeiro. O curso está sob a responsabilidade atual da Comissão Pastoral da Terra (CPT), com apoio direto da Empresa de Assistência Técnica e Extensão Rural do Rio de Janeiro (EMATER Rio) de Nova Iguaçu. A Escolinha de Agroecologia foi fundada em 2007, com o objetivo de possibilitar a construção de uma identidade e o protagonismo do agricultor para o fortalecimento do movimento de assentamento, a partir da aproximação com a temática da Agroecologia e a compreensão da necessidade de estabelecer um novo modelo produtivo no campo e na cidade, resgatando, assim, valores e práticas culturais que busquem a conservação e a preservação do ambiente.

A iniciativa de promover a Escolinha de Agroecologia foi da Comissão Pastoral da Terra - Regional Baixada Fluminense (CPT- RJ), baseando-se em experiência similar desenvolvida na região norte do estado do Rio de Janeiro. Foi uma experiência alternativa, construída pelos agentes da Comissão Pastoral da Terra (CPT), das comunidades de assentados e pelo movimento sindical dentro do modelo que se conhece desde 2008.

Ao longo dos anos, as parcerias foram aumentando, com a EMATER Rio fornecendo instrutores e compartilhando a coordenação com a CPT, cabendo à EMATER a coordenação técnico-pedagógica, e à CPT, a coordenação administrativa; a EMBRAPA cede instrutores; a Empresa de Pesquisa Agropecuária do Estado do Rio de Janeiro (PESAGRO) olericultura também recebe os alunos em visitas técnicas; a UFRRJ apoia a Escolinha cedendo ônibus para algumas visitas técnicas, além de instrutores; as Secretarias de Agricultura de Japeri e Queimados cedem suas kombis para o transporte de alunos; o Ministério da Agricultura, Pecuária e Abastecimento (MAPA) viabiliza as atividades da Escolinha através de apoio financeiro, assim como as ONGs e ASPTA - esta última, com participação também de instrutores. A Escolinha também se integra ao projeto de Banco Comunitário de Sementes de Adubos Verdes do MAPA (EMATER, 2013).

O fortalecimento dos movimentos sociais, em particular dos movimentos ambientalistas e das organizações não-governamentais (ONGs), também contribui para redefinir o espaço de atuação da agricultura familiar e abrir novas oportunidades. Os movimentos sociais e ONGs vocalizam uma parte das preocupações da sociedade com o meio ambiente, com a segurança dos alimentos e com questões de equidade que teriam dificuldade de se expressar no mercado de forma imediata (BUAINAIN; SOUSA FILHO; SILVEIRA, 2002). Uma experiência iniciada em 2005, em Campos dos Goytacazes, nas dependências da Universidade Federal Fluminense, promoveu encontros com o objetivo de formação, sendo posteriormente transferida para o as- 
sentamento de Zumbi dos Palmares na mesma cidade. O modelo da escola popular de Campos foi a inspiração para o início dos trabalhos da Escolinha de Nova Iguaçu, também fundamentada na troca de experiências e no diálogo, ocorrendo um debate técnico e político a partir das experiências práticas em Agroecologia.

Durante os encontros semanais da EA, identificou-se a prática de educação popular, ao considerar o conhecimento produzido no modo de vida destes agricultores e na práxis das ações agroecológicas. Exige-se que os agricultores não apenas dominem o conhecimento da ciência, mas que não abandonem outras referências de produção de conhecimento construídas nas próprias práticas e lutas sociais.

Com base na necessidade de encontrar a educação popular junto aos agricultores de Nova Iguaçu, principalmente entre a CPT e a EA, ela ganhou importância na metodologia de ensino da Agroecologia; mesmo sem ocupar uma zona teórica, tem sido levantada pelo grupo que está à frente dos conteúdos da EA, os quais são profissionais da EMATER que alcançam uma verdadeira práxis. Eles já entenderam a necessidade de articulação entre a práxis da pesquisa e a práxis agroecológica, bem como a identificação de estratégias para uma transformação social dentro das próprias circunstâncias em que o rural está inserido, mesmo que os alunos da EA não tenham consciência da práxis ou da educação popular implementada. Esse ensino é feito em espaços institucionais e de vida, por meio do saber e do fazer de cada agricultor que participa da EA, de maneira valorizada, ou seja, consegue-se ampliar o universo de conhecimento e possibilita-se a mudança no universo dessas pessoas envolvidas.

Na região da Baixada Fluminense, há predominância de agricultores familiares, sendo que, na área de abrangência da Escolinha de Agroecologia de Nova Iguaçu/RJ, cerca de $50 \%$ são oriundos de movimentos de ocupação organizada, alguns gerando projetos oficiais de assentamento. A EA vem aumentando a abrangência de sua intervenção a cada ano. Em 2007 e 2008, ficou restrita a alunos do município de Nova Iguaçu, com predominância da comunidade de Marapicu. Atualmente sua abrangência ultrapassa o município de Nova Iguaçu. A primeira sede da EA foi em Marapicu, e sua transferência para o centro de Nova Iguaçu facilitou o acesso aos interessados de outras cidades do estado, desde o ano de 2008.

A EA é uma atividade de formação informal, visando à apropriação pelos agricultores de processos técnicos para serem aplicados dentro de um sistema agroecológico de produção. Apresentam segmentos teóricos e práticos de conservação do solo e da água, métodos alternativos de controle de pragas e doenças, cuidados ao meio ambiente, criações de animais, entre outros.

O agricultor familiar não é um personagem passivo, sem resistência diante de forças avassaladoras vindas de fora e de cima do seu universo. Pelo contrário, ele constrói sua própria história nesse emaranhado campo de forças que vem a ser a agricultura e o meio rural inseridos em uma sociedade moderna (WANDERLEY, 2001). Para Carneiro (1999), mesmo havendo um intenso debate sobre os princípios definidores do conceito de agricultura familiar, esta seria uma unidade de produção onde a terra, o trabalho e a família estão intimamente ligados.

A agricultura familiar tem sua importância nos aspectos sociais, pela capacidade de contrabalançar a tendência, tão própria à sociedade brasileira, de desva- 
lorizar o meio rural como lugar em que seja possível construir melhores condições de vida e de encará-lo como o local em que permanecem aqueles que ainda não enveredaram pela 'verdadeira aventura civilizatória', a urbana (ABRAMOVAY, 1998).

\section{Metodologia aplicada na contextualização do espaço social}

A descrição dos agricultores participantes da EA, sua organização política por associações, ou integração na Feira da Roça, situa as interdependências espaciais e temporais a que estão sujeitos os agricultores no município de Nova Iguaçu, os quais, majoritariamente, resistem à vida urbana.

Para o presente estudo, englobaram-se informações constantes no cadastro da EA, arquivadas pela EMATER, entre os anos de 2008 e 2015, somando-as às evidências empíricas relatadas pelos técnicos deste órgão para a construção de dados que complementassem o caso estudado e norteassem a aplicação da metodologia.

Inicialmente, fez-se necessária uma ampla revisão bibliográfica, tornando-se fundamental também a pesquisa de campo, para a compreensão da Escolinha de Agroecologia, na localidade de Nova Iguaçu, a fim de caracterizar os instrumentos locais que exercem um poder social sobre realidade atual. Dessa forma, foram elaboradas entrevistas com os alunos e ex-alunos da Escolinha de Agroecologia, diretamente envolvidos na construção do possível desenvolvimento rural.

Este estudo propõe visibilidade à EA e a seus participantes, permitindo caracterizar-se pelo levantamento qualitativo, centrado no estudo de caso exploratório. Como afirma Triviños (1987), o estudo de caso é definido como aquele que examina um fenômeno em seu ambiente natural, pela aplicação de diversos métodos de coleta de dados, sendo estes aqui pautados pela descrição e aproximação das complexidades nas relações sociais presentes na área estudada, possibilitando, dentre outros aspectos, a compreensão dos processos práxicos dos indivíduos envolvidos. Tal perspectiva sobre a pesquisa qualitativa é descrita por Minayo (2002), ao afirmar que a dinâmica das relações sociais são depositárias de crenças, valores, atitudes e hábitos. Trabalham com a vivência, com a experiência, com a continuidade e também com a compreensão das estruturas e instituições como resultado da ação humana objetiva. Ou seja, desse ponto de vista, a linguagem, as práticas e as coisas são inseparáveis.

Este processo de aproximação foi realizado desde janeiro de 2015, estendendo-se até setembro do mesmo ano. Esse tempo nos espaços em que transitam os agricultores, além da EA, atendeu à exigência de imersão no contexto investigado, um princípio básico da pesquisa qualitativa, que postula a ideia de se pesquisarem os fenômenos no próprio contexto, proporcionando uma multiplicidade de aspectos inerentes ao objeto de estudo.

No decorrer do processo de pesquisa de campo, para a coleta de dados, não se interveio nas situações vividas, pois se assumiu, no desenvolvimento da pesquisa, uma atitude de observador direto da realidade estudada. Ao todo, foram onze agricultores, dois profissionais da EMATER de Nova Iguaçu, um integrante da AS-PTA e dois integrantes da CPT, totalizando dezesseis entrevistas. Durante esse período, foram realizadas entrevistas semiestruturadas, utilizando como técnica de amostra- 
gem o Snowball ou bola de neve. A abordagem aos entrevistados ocorreu em encontros distintos, na EA, na Feira da Roça de Nova Iguaçu, na CPT, na EMATER e em alguns eventos na cidade no ano de 2015.

O conteúdo de uma comunicação é tão rico e apresenta uma visão polissêmica valiosa, que, notadamente, permite ao pesquisador qualitativo uma variedade de interpretações (MINAYO, 2002). Segundo este ponto de vista, produzir suposições, através da análise do conteúdo de uma determinada mensagem, será uma ação embasada por hipóteses fundamentalmente teóricas, variando conforme as concepções de mundo, as situações concretas de seus mensageiros ou ouvintes, proporcionando de forma concreta a visibilidade conforme o contexto histórico e social de sua produção e recepção.

O tratamento dos dados colhidos, isto é, a interpretação, realizou-se a partir dos conteúdos evidenciados nas fases anteriores, no sentido da especificação das categorias. Ao analisar a fala do agricultor, a partir das respostas das entrevistas, principalmente quanto a valores, percebemos algumas características e outras informações que surgiram durante as abordagens. Para proceder a essa interpretação, tomamos como referência a análise de conteúdo proposta por Bardin (1977), que a define como um conjunto de técnicas de análise das comunicações, visando obter, na descrição do conteúdo das mensagens, indicadores que permitam a interferência de conhecimentos relativos às condições de produção dessas mensagens.

Essa especificação ou análise final é baseada em significações de palavras e frases que esclarecem comportamentos e opiniões dos sujeitos investigados (BARDIN, 1977). Com vistas a responder ao problema e aos objetivos a que esta pesquisa de dissertação de mestrado se propôs, os dados coletados previamente foram analisados por meio da análise categorial, agrupada analogicamente.

Portanto, a interpretação dos dados deu-se pelo método da análise de conteúdo, respaldada pelas observações. O processo de formação das categorias concretizou-se conforme a forma prevista por Bardin (1977); após a seleção do material e a leitura flutuante, a exploração foi realizada através da codificação.

Nesse ponto, as tentativas de interpretação nos remeteram ao referencial teórico, cujo embasamento fez-nos chegar, por meio de hipóteses, ao significado daquilo que se encontra nos discursos, manifestado explicitamente ou de forma velada, resultando no estabelecimento de quatro categorias. As unidades de registro e unidades de contexto amparam a construção das presentes categorias. Construídas com o intuito de respaldar as interpretações e inferir os resultados, as categorias representam a síntese do aparato das significações identificadas no decorrer da análise dos dados do estudo.

A unidade de registro foi aplicada como primeiro recorte, em razão de características comuns entre bibliografia e transcrição de entrevistas. O movimento práxico ocorre entre a teoria e os dados coletados, e vice-versa, onde as categorias foram se tornando claras e adequadas ao objetivo proposto. A unidade de contexto é demonstrada nas projeções pessoais, ao mesmo tempo em que se internalizam, os significados e valores tornam-se parte de nós, como indivíduos preenchidos de sentimentos subjetivos, nos lugares objetivos que ocupamos no mundo. A catego- 
ria é visível na definição que perpassa os objetivos de conceituação das unidades anteriores, permanecendo sustentada e em contato com sua concepção de mundo, formando, dessa maneira, a categoria em si, pela compreensão do valor histórico, da função na vida, dos direitos e deveres.

Entre as diversas formas de buscar compreender o que dizem as reflexões dos agricultores e sua rede de relações e articulações, no tocante ao saber popular, não se teve dúvida em buscar as narrativas como ferramenta de produção dos dados e possibilidade de tornar mais reflexivo este momento, principalmente por meio da técnica bola de neve, na qual cada entrevistado indicava outra pessoa para ser entrevistada. Na busca de saberes, a narrativa é uma estratégia de pesquisa, pois só o próprio agricultor é legitimado para essa tarefa de expressar, através de suas histórias, os saberes adquiridos individual e coletivamente na sua atividade, possibilitando o que chamamos de exercício práxico.

\section{Narrativas, expressões e saberes}

Diante do exposto, procurou-se, a partir dos dados produzidos nas entrevistas e, posteriormente, nas análises das narrativas dos entrevistados, pautados nos objetivos propostos para este conhecimento, sistematizar as análises dos dados através de categorias, as quais irão subsidiar informações sobre a construção do discurso do agricultor.

Segundo levantamento feito através da EMATER/Nova Iguaçu, em 2015, com 469 fichas de inscrição da Escolinha de Agroecologia, entre os anos de 2008 e 2015, pode-se afirmar que $70 \%$ (328 cadastros) dos cadastrados possuem escolaridade apenas até o nível fundamental, o restante do percentual possui ensino médio completo ou incompleto, sendo 55\% (258 inscritos) mulheres, e 45\% (211) homens, o que difere do censo de Nova Iguaçu apresentado anteriormente. Uma média de 65\% (305) dos agricultores de Nova Iguaçu têm como única fonte de renda sua produção agrícola, $10 \%$ (47) são aposentados, $20 \%$ (93) possuem outra fonte de renda para complementar sua produção, como benefícios sociais, e 5\% (22) recebem auxílio de parentes. Com base nessa última informação, podemos considerar Nova Iguaçu um espaço de multifuncionalidades no campo. Os agricultores participantes das entrevistas são provenientes, em sua maioria (65\%), de municípios rurais, tanto do estado do Rio de Janeiro como de Minas Gerais, Espírito Santo e Ceará. Essas informações mostram que, a princípio, esse grupo de agricultores faz parte do grande fluxo migratório ocorrido a partir dos anos 70 e 80 em direção às metrópoles.

$\mathrm{Na}$ atividade agrícola, cuja lógica de reprodução social é determinada pela realização de uma produção orientada para a subsistência, obedecendo à satisfação de índices de rentabilidade e de tentativa de produtividade crescente, as estratégias de reprodução não se limitam a reproduzir, isto é, subsistir e permanecer. Elas também dão conta das novas necessidades e dos novos desafios que são continuamente gerados pelas transformações econômicas e sociais (SCHNEIDER, 2003).

A primeira categoria descrita, a reprodução social, pode ser entendida pelo agricultor familiar como a que se constrói na sua própria história, no campo de forças 
que vem a ser a agricultura e no meio rural inserido em uma sociedade moderna. $E$ ele o faz recorrendo à sua própria experiência (camponesa) e procurando adaptar-se às novas "provocações" e desafios do desenvolvimento rural (WANDERLEY, 1995). Carneiro (1999) considera, na reprodução social, além dos bens materiais, outros tipos de bens, simbólicos, que são transmitidos de uma geração a outra, não somente como elemento da produção ou do trabalho, mas também como elemento da reprodução e transmissão de valores.

Ao analisar a categoria ser social e cultural, de forma profunda na experiência da $E A$, compreende-se que para resgatar e construir uma identidade do homem e da mulher do campo é necessário que haja mudanças culturais e comportamentais. Tais mudanças são difundidas pela metodologia do curso de Agroecologia da EA de Nova Iguaçu, chegando a denominá-las como uma práxis da educação popular. A educação do campo, enquanto fundamento histórico, recria o conceito de agricultor, utilizando o espaço rural como símbolo significativo, referindo-se, assim, ao conjunto de trabaIhadores que habita este território cercado por saberes. Na prática, os agricultores precisam quebrar os preconceitos, no sentido de mudar a visão que a sociedade brasileira tem em relação a eles próprios, e, nesse contexto, eles mesmos, na EA, são estimulados a entender o lugar social a que são direcionados e as possibilidades que podem ser alcançadas. A EA, existente tanto para os assentados quanto para outros agricultores familiares, tem auxiliado na mudança de paradigma, contribuindo com as lutas por melhorias na vida rural.

A questão cultural valoriza o conhecimento empírico acumulado ao longo de anos de processo de vivência dos agricultores. E o saber popular fomentado pela EA apresenta-se como necessário e culturalmente valorizado, na medida em que a sociabilidade entre os alunos torna-se, também, agente de transformação dos padrões de produção/consumo na escala do local entorno da Agroecologia. Ainda, o patrimônio cultural alimentar está relacionado aos processos participativos e democráticos, que incluem os produtores rurais nos processos decisórios e de gestão nas atividades desempenhadas por eles, assim como na organização de redes sociais e de representações dos diversos segmentos da população rural.

Em um dos relatos, a possibilidade de vínculos é referida paralelamente à formação da Escolinha. Neste sentido, a pesquisa auxiliou no resgate de experiências compartilhadas sobre a atividade com a terra em si e em seu sentido cultural. É percebida a racionalidade ambiental e cultural do meio rural sobressaindo-se à questão econômica. A valorização do produtor rural já aparece como um ponto de destaque, e demonstra-se, assim, como está caminhando para o aumento da espontaneidade e naturalidade cultural na construção de uma nova identidade cultural.

A terceira categoria é a do poder social. Quando reconhecemos a potencialidade que a questão rural e seus desdobramentos alcançam, é possível compreender a territorialidade como sendo uma expressão do poder social, cabendo à Agroecologia contribuir tanto para a realização de análises críticas sobre a agricultura produtivista quanto para direcionar uma alternativa adequada ao manejo de agroecossistemas, na perspectiva da agricultura familiar utilizá-las na recuperação das economias rurais e da sustentabilidade social. 
Entre os principais problemas enfrentados pelos produtores observados durante a realização das entrevistas, estão os que se referem ao solo degradado, à enorme burocracia para recebimento de crédito rural, aos serviços precários e à total precariedade dos serviços públicos na região em que residem. O enfrentamento das grandes dificuldades interfere diretamente na reprodução social, na sustentabilidade ecológica, social e econômica. Durante toda a pesquisa, foi verificado que o curso ofertado pela EA tem sido marcado pelas negligências do poder público.

A última categoria trabalhada é a da atividade agroecológica. As práticas de transição agroecológicas vêm sendo adotadas há vários anos na região, fato este favorecido pelo baixo poder aquisitivo dos agricultores locais, pela dificuldade de acesso às grandes fornecedoras de insumos sintéticos, pela estrutura fundiária e pela proximidade com o consumidor, o que influencia na busca de qualidade pelo agricultor.

Dessa forma, a agricultura e a alimentação desempenham um papel importante na manutenção do tecido social e cultural no território em questão. A agricultura familiar valoriza, respeita e compartilha seu modo de vida, o patrimônio cultural e natural, ofertando produtos e serviços de qualidade e proporcionando bem-estar aos envolvidos, socializando os seus saberes e fazeres.

Conforme se pode verificar, os agricultores demonstram conhecimento e percepção aproximados ao que se considera pertinente pelo poder trabalhado pela EA. As dimensões do processo de aquisição de poder estão ligadas ao desenvolvimento da percepção, da consciência desse poder. Observou-se a importância dos movimentos sociais, que adquirem bastante relevância, especialmente quando se trata da organização social no assentamento de Marapicu, de Nova Iguaçu, onde se evidenciou uma oxigenação nos movimentos sociais através da prática agroecológica. Estes movimentos representam espaços importantes de sociabilidade e de criação de laços afetivos, pautando a vida social e cultural dos assentados e dos demais agricultores da região.

Embora se tenha avançado em muitos aspectos, no que se aproxima da educação popular, a exemplo de leis, métodos pedagógicos, dentre outros, ainda há muito que se construir para que se tenha uma práxis de qualidade também para os cidadãos rurais. A práxis na EA é entendida como categoria central da filosofia concebida não só como interpretação do mundo, mas também como guia de sua transformação, que não é outra senão o marxismo (VÁZQUEZ, 1968). Observa-se que é preciso dar atenção às contradições decorrentes das relações entre Estado e sociedade civil, na práxis da educação do campo, de forma geral, discutindo-se como são vistas na EA as próprias concepções de Estado que emergem dessa práxis, as quais exigem interpretações e tomada de posição, na perspectiva de escolher as estratégias a seguir. Há necessidade de considerar como uma possibilidade de que os agricultores, de maneira organizada, possam mudar a regra do jogo e criar uma contra-hegemonia.

Assim, compreende-se que o poder não deriva simplesmente da posse ou do uso de certos recursos dados aos agricultores, mas também da capacidade de influenciar um indivíduo ou grupo sobre outrem, resultante das ações metodológicas da educação agroecológicas proposta pela EA. Todo o processo de reflexão que ocorre na EA fomenta um olhar coletivo e unificado, com o objetivo de contribuir na manutenção das ações da agricultura familiar agroecológica. 
A pesquisa, apesar das limitações e implicações teóricas e empíricas relativas aos processos da realidade vivida, encontrou na Escolinha de Agroecologia um esforço geral para destacar a importância da educação popular para os agricultores de Nova Iguaçu, fortalecendo a identidade e a reprodução social da cultura rural, mesmo numa localidade de grande expressão urbana.

\section{Considerações finais}

No município de Nova Iguaçu, a agroecologia apresentada aos agricultores pela EA, como possibilidade de desenvolvimento, apesar do esgotamento do padrão de agricultura convencional, não é realidade entre os entrevistados, o que requer, com urgência, repensar formatos tecnológicos da produção agrícola convencional restante na região, criando condições para que os princípios da produção agroecológica possam ser perpetuados pelo segmento da agricultura familiar local.

Todos os laços e redes que foram criados desde a efetivação da educação popular na EA constituíram a consciência, a reflexão e a ação dos agricultores através das práticas agroecológicas, que se tornaram intervenções com práxis em Nova Iguaçu e libertadoras das condições - desumanas muitas vezes - impostas ao meio rural. A oferta de possibilidades dada aos agricultores pela EA tem sido através da práxis agroecológica, na perspectiva de formar novas relações micro e macroestruturais, como a criação ou a reinserção de espaços reflexivos, oportunidades, valorização do saber popular, manutenção da vida rural com cidadania e um compromisso com as novas ruralidades culturais de trabalho e produção agroecológica.

Os objetivos a serem alcançados no processo de fortalecimento das relações entre os agricultores familiares da localidade e sua reprodução social, estrategicamente constituída na luta como atores ativos, quer no Assentamento de Marapicu, nas cooperativas de trabalho, na participação da Feira da Roça de Nova Iguaçu ou na Articulação Metropolitana de Agroecologia, visam a implementação de um desenvolvimento digno e organizado, com produção de alimentos saudáveis e melhora nas condições das famílias envolvidas. O movimento social que originou a EA defende que haja um projeto justo e igualitário de oportunidades aos produtores rurais de Nova Iguaçu, contemplando um modelo de desenvolvimento agroecológico em que permaneça o respeito ao saber popular, (re)construído no discurso agroecológico, como uma categoria essencial aos agricultores familiares.

Entre as principais questões levantadas durante esta pesquisa, está o processo de instrumentalização das dimensões da territorialidade na cidade de Nova Iguaçu, com o intuito de caracterizar as novas percepções no desenvolvimento rural executadas nessa localidade através da Agroecologia, bem como o poder social potencializado pela EA. Dadas essas perspectivas, tem-se observado a construção e disseminação da Agroecologia há algumas décadas, por diferentes categorias de produtores familiares e assentados, em articulação com redes e organizações da sociedade civil, pesquisadores, extensionistas, agências de cooperação e gestores de políticas públicas.

É na travessia agroecológica que os agricultores familiares de Nova Iguaçu se 
revelam cada vez mais claramente como componentes da organização e manutenção do meio rural. Assim, sua identidade significa uma participação na trama das relações sociais, por sua legitimação, vínculos, enfim, por seu papel ativo nas novas relações e redes que se formam e transformam com a construção da consciência crítica, política e participativa. Tal superação, plena de vida, com seus sabores e dissabores, decorre num novo momento histórico, numa nova alternativa de prática, que trança, nos viés da vida, o empoderamento desses cidadãos, antes relegados às inconsistências de políticas públicas irrisórias.

Atualmente, quando se analisa o espaço rural iguaçuano, verifica-se que a produção agrícola familiar assumiu inúmeras formas de reprodução. Entretanto, um conjunto relevante de agricultores mudou sua lógica de produção para a agroecologia, criando novas estratégias de produção, permanecendo no ambiente rural ou periurbano. Dentre os entrevistados, não foi encontrado nenhum caso de pluriatividade, fato decorrente da efetiva importância do trabalho agroecológico como instrumento revigorante do trabalho agrícola. Contudo, foi verificado um desempenho que ultrapassa este conceito de pluriatividade; são outras funções ressaltadas na agricultura familiar iguaçuana, como a questão ambiental ou ecológica, territorial e social, que denominaremos multifuncional. A agricultura familiar da região estudada é extremamente diversificada, sendo evidenciada, em sua maioria, por famílias que vivem e exploram minifúndios em condições de pobreza.

No estudo de caso dos agricultores familiares agroecológicos específicos, encontrados em Nova Iguaçu, ocorre um enfraquecimento devido à descontinuidade espacial, que empobrece os laços de relação e, possivelmente, o ser social e cultural, na reprodução e na manutenção dos usos diferenciados da terra, tornando-se a EA um ponto de união dessas relações rurais da região.

A possibilidade reprodutiva rural é o resultado de uma concentração de conhecimentos sobre técnicas de trabalho que não vêm diretamente da academia ou da escola tradicional, mas das relações entre pessoas, ambiente e suas influências, fomentadas pela EA. Nesse sentido, o esforço de sustentabilidade implica reconhecer a existência desse saber, construído na história de vida, no esforço de sol a sol, no encontro com o outro - possuidor das trajetórias e referenciais semelhantes - e na práxis agroecológica, perpassando a construção de saberes ajustados na EA, para fortalecer o poder social na agricultura, capaz de indicar crescentes índices de sustentabilidade.

O importante aqui é que os agricultores não são apenas reprodutores das estruturas em que se inserem, mas têm capacidade de alterar a correlação de forças dentro de um determinado campo, conquistando a cidadania através do conhecimento das leis, do acesso aos serviços no território em que se estabelecem, tornando-se um direito a prática social.

A dinâmica da construção do tecido social está inserida do ponto de vista dos direitos, uma atenção compartilhada para que a dignidade humana seja assegurada e respeitada. A rede de proteção social percebida na construção da metodologia da bola de neve caracterizou a forte presença do empoderamento. $\mathrm{O}$ acesso à rede de serviços é necessário para que se possam desenvolver enquanto cidadãos. 
Fica nítida compreensão das desigualdades no território no entendimento dos agricultores: quanto maior os esforços feitos para uma aproximação com o território, mais as desigualdades internas se tornam visíveis e passíveis de serem superadas. Os agricultores são referenciados pelos recursos simbólicos e informacionais que se se estabelecem nas práticas dos movimentos sociais e em toda articulação presente, uma relação intrínseca entre mediação e informação, responsáveis por configurar redes que articulam e estabelecem as posições discursivas dos atores sociais. É a partir desses posicionamentos que os sujeitos buscam ver significados nas diferenças que demarcam suas identidades e demandas, questionando e desafiando os códigos que determinam o sentido da realidade social.

\section{Referências}

ABRAMOVAY, Ricardo. Agricultura familiar e serviço público: novos desafios para a extensão rural. Cadernos de Ciência e Tecnologia, Brasília, v. 15, n. 1, jan./abr. 1998.

BARDIN, Laurence. Análise de conteúdo. Lisboa: Edições 70, 1977.

BUAINAIN, A. M.; SOUZA FILHO, H.; SILVEIRA, J. M. Agricultura familiar e condicionantes da adoção de tecnologias agrícolas. In: LIMA, D.; WILKINSON, J. (Orgs.). Inovação nas tradições da agricultura familiar. Brasília, CNPq/Paralelo, 2002.

CARNEIRO, Maria Jose. Agricultores familiares e pluriatividades: tipologias e políticas.In: Costa, L. F. C.; Moreira, R. J.; Bruno, R. (Orgs.) Mundo rural e tempo presente. Rio de Janeiro.Mauad, 1999.

EMATER/Nova Iguaçu. Engenheira Agrônoma da EMATER RIO. Documento de Sistematização da Escolinha de Agroecologia. Escritório local de Nova Iguaçu/RJ, 2013.

MINAYO, M. C. S. (Org.). Pesquisa social: teoria, método e criatividade. Petrópolis: Vozes, 2002.

SCHENEIDER, Sergio. Teoria social, agricultura familiar e pluriatividade. Revista Brasileira de Ciências Sociais, v. 18, n. 51, fev. 2003.

TRIVIÑOS, A. N. S. Introdução à pesquisa em Ciências Sociais: a pesquisa qualitativa em Educação. São Paulo: Ática, 1987.

WANDERLEY, M. de N. B. A ruralidade no Brasil moderno. Por un pacto social pelodesenvolvimento rural. Enpublicacion: ¿Una nuevaruralidaden América Latina?. Norma Giarracca. CLACSO, Consejo Latinoamericano de Ciencias Sociales, Ciudad Autónoma de Buenos Aires, Argentina. 2001. ISBN: 950-9231-58. Disponible en: <http://bibliotecavirtual.clacso.org.ar/ar/libros/rural/wanderley.pdf>.

. O camponês: um trabalhador para o capital. Cadernos de Difusão de

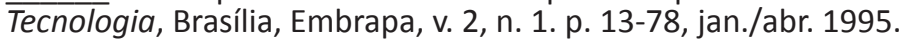

